\title{
Integration Takes Managed Care in Different Directions: Horizontal, Vertical, and Beyond
}

If there is one constant in the health care arena, it is change. One of the most prevalent changes has been the move toward horizontal and vertical integration, resulting in "full-service" systems. But is this a passing fad or the way of the future?
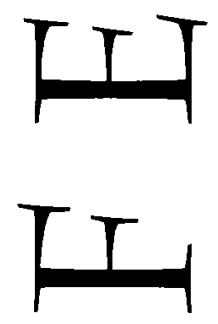

BRUCE GOLDFARB

Bruce Goldfarb is a Baltimore, MD-based freelance medical and health care writer: Copyright $(\mathcal{C}$ 1997, Academy of Managed Care Pharmacy, Inc. All rights reserved.'

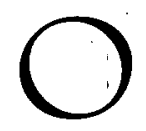
ne of the most significant trends in health care today is the development of integrated systems, large organizations that provide a full range of health care services from neonatology to geriatric long-term care. Proponents of managed care describe seamless systems offering a coordinated continuum of health care services that is more economical and of higher quality than boutique-style medicine that was prevalent under the traditional indemnity insurance system.

Some industry observers predicted the emergence of "super meds," a halfdozen or so prominent health care corporations that would dominate the industry with a full complement of hospitals, physician networks, pharmacy benefit programs, home health services, and the financial mechanisms to act as insurers. In this system of "brand name medicine," a single company could provide primary

Continued on page 263 
care, specialty care, ancillary care, and rehabilitation and administer the benefit, as well.

To some degree, this type of system already exists in some areas of the country where managed care is highly evolved. According to Paul Ellwood, M.D., president of the Jackson Hole Group, a health care think tank, "We already have brand name medicine in California and Minnesota. The dinner table conversation these days is, "Who do you go to, Kaiser or PacifiCare?"”

While the "super meds" have not yet come to pass, consolidation is occurring in the health care industry at a breakneck pace. Multi-million dollar mergers and acquisitions are creating health care giants that will have a profound impact on the provision of pharmacy services and products.

\section{FROM COMPETITOR TO PARTNER}

The two basic types of integration are horizontal and vertical. In a horizontally integrated system, two or more similar organizations group together to form a larger entity, primarily in an effort to capture a larger market share. Horizontally integrated systems are able to take advantage of economies of scale, such as leveraging buying power from vendors.

Examples of horizontal integration would include the $\$ 7.1$ billion merger of Hoechst AG and Marion Merrell Dow, and the $\$ 14.8$ billion acquisition of Wellcome by Glaxo, both in 1995. More recently, Rite Aid, one of the nation's largest retail pharmacy chains, was acquired by its top rival, Revco, in a deal estimated to be worth $\$ 1.8$ billion. Aside from eliminating one of its primary competitors, experts indicate that the acquisition will position Revco to take better advantage of larger managed care contracts

Horizontal integration is visible throughout the spectrum of health care. Hospitals often merge into regional systems to provide greater regional coverage and a fuller range of clinical services. Health maintenance organizations
(HMOs) will merge into läger networks to become more attractive to multi-state employers and to dissipate the consequences of full-risk contracting.

\section{VERTICAL INTEGRATION: THE MORE COMMON MOVE}

A more common type of integration is vertical - the grouping together of different yet related organizations. Rather than having a, primary goal of increasing market share, systems are integrated vertically to be able to offer a continuum of services. For example, an $\mathrm{HMO}$ may acquire a hospital to handle a portion of its inpatient care, or a hospital may link up with a physician network to better operate as a full-service managed care organization.

Pharmacy benefit management (PBM) companies have become commodities for mergers and acquisitions, according to Elisa Cascade, senior manager at the Lewin Group. There has been vertical integration among three pharmaceutical companies and PBM firms in recent years: Merck and Medco Containment Services, SmithKline Beecham and Diversified Pharmaceutical Services, and Eli Lilly and PCS Health Systems. In 1996, MedPartners/Mullikin made a $\$ 2.5$ billion acquisition of Caremark, which provides prescription benefit management for 15 million members. The combined entity became the nation's largest physician management company. In early 1997, Columbia/HCA, the nation's largest hospital chain, announced the intention to merge with Value Health, which includes its PBM subsidiary, Value $\mathrm{Rx}$, the largest of its type in the nation.

Pharmaceutical companies "at first thought of PBMs as a way to get their products onto formularies" used by managed care companies, says Cascade: ? "These pharmaceutical companies paid a very big premium for these pharmacy benefit management companies. Now that they've spent a lot of money for these companies, they're trying to figure out what else they can turn them into."

Vertically integrated systems, while appealing to payors interested in onestop shopping, have been met with uneven success. While many large vertically integrated systems thrive, some find it difficult to nurture widely divergent and sometimes conflicting organizational entities. Health systems that spent part of the late 1980s building large provider networks spun them off in the 1990s. Foundation Health Corp., a prominent West Coast managed care company, sold almost all of its physician network interests to FPA Medical management in 1996. PacifiCare, which includes pharmacy benefit management as a major portion of its book of business, sold its HMO operations in Florida, a highly competitive managed care market. Numerous HMOs and hospital systems are selling physician groups as well, preferring to do business by contract rather than outright ownership.

In the case of pharmacy benefit companies, vertically integrated organizations may risk running afoul of federal antitrust laws. The acquisition of Medco Containment Services by Merck attracted the attention of Congressional investigators after the General Accounting Office suspected Medco of unfairly favoring Merck products in the months before the purchase. However, the investigation wielded no evidence of wrongdoing. It is important to note that regulators also have scrutinized the relationships between SmithKline and DPS and between Eli Lilly and PCS. And, again, no illegal or unethical activities were uncovered.

Some observers suggest that the flurry of mergers and acquisitions will abate while companies reorganize and rethink their marketing strategies. For example, Allan Fine, senior manager at Ernst and Young, says, "There will be a redefinition of marketing, positioning, and sales strategies on the part of pharmaceutical companies," adding, "From the standpoint of the managed care company, they want to ratchet down the cost of pharmaceuticals. On the part of pharmaceutical companies, they want to gain inclusion on formularies."

One way both objectives can be 
met is through "strategic partnerships," arrangements in which two companies collaborate to their mutual benefit. A strategic partnership can be as formal as a joint venture, in which parties share risk, or simply an agreement to market two products or services in tandem.

\section{OUTSOURCING OFFERS POPULAR OPTION}

Outsourcing is another area that has grown significantly. This involves contracting with a private firm to handle functions that previously had been performed internally. To date, outsourcing. has been most common in the area of food service, in which hospitals, schools and other institutions outsource food service activities to companies such as Marriott. That trend also is occurring within the health care industry.

Cascade uses the term "virtual integration" to describe a health system in which many services are provided by. outsourcing. "What people are finding is that it's more cost-effective to contract it out rather than to build the bricks and mortar themselves," she says. Opportunities are greatest in high-cost niche areas, such as chemotherapy, home infusion services, and parenteral nutrition.

Outsourcing is becoming an increasingly popular option as a means to provide services that otherwise cannot be performed efficiently. Contracting activities to outside companies that traditionally had been performed within the organization allows health care providers to take advantage of economies of scale that otherwise could not be achieved. For example, at the Detroit Receiving Hospital, outsourcing the preparation of total parenteral nutrient (TPN) solution to a subsidiary of Baxter Healthcare allowed the 340-bed acute care hospital to eliminate a technician position, reassign pharmacyistaff to higher-priority clinical activities, and save $\$ 59,000$ a year, according to Richard Smolarek, associate director of the hospital pharmacy. Orders for TPN are downloaded by computer to the vendor, located about 20 miles away and delivered by courier the same evening. "We were being challenged to decrease personnel and to find a way to get more time for pharmacists for clinical activities," explains Smolarek. "We wanted to save money, do things with less personnel, and have the best possible quality. Outsourcing TPN was something that was easy to do."

As economic pressures continue to intensify, interest in outsourcing is expected to rise, according to Ken Abramowitz, analyst at Sandford C. Bernstein, a New York-based health care securities firm. "Pressures are so intense that people are convinced they can't do everything themselves, that they have to contract with professionals who specialize," he says. "If someone outside can do a better job of lowering your costs than you can yourself, you have to transfer that business to that other person."

Health systems and HMOs across the nation are examining internal operations to identify likely candidates for outsourcing, with pharmacy often at the top of the list. For example, the Volunteer Hospital Association is in the process of identifying a company to outsource pharmacy management for its 1,400 member facilities.

Pharmacy lends itself to outsourcing because operations have more similarities than differences in various health systems and, therefore, only can differentiate themselves on the basis of cost. The pharmacy is "an area where health care providers are unable to differentiate themselves in the marketplace," says Michael F. Corbett of the Outsourcing Institute. "It is unlikely that a hospital would be able to achieve the economies of scale like somebody who does pharmacy operations for a living."

Virtual integration and the opportunities it portends for pharmacy may be the best way for health systems to cope with growth of managed care. "The trend is to contract with someone else for whatever is needed, to contract with an outside pharmacy benefit manager to get better control over costs. HMOs are becoming marketing agents and realizing that it's best to contract out everything else to various qualified parties," says Abramowitz, adding, "Vertical integration is history." 